\title{
Investigation of Current Control Techniques of AC-DC Interleaved Boost PFC Converter
}

\author{
A. Inba Rexy ${ }^{*}$, R. Seyezhai ${ }^{2}$ \\ ${ }^{1}$ Department of Electrical and Electronics, Loyola-ICAM College of Engineering and Technology, Chennai, India \\ ${ }^{2}$ Department of Electrical and Electronics, SSN College of Engineering, Chennai, India \\ Email: inbarexy.a@licet.ac.in, seyezhair@ssn.edu.in
}

Received 6 March 2016; accepted 24 April 2016; published 27 April 2016

Copyright ( 2016 by authors and Scientific Research Publishing Inc.

This work is licensed under the Creative Commons Attribution International License (CC BY).

http://creativecommons.org/licenses/by/4.0/

(c) (i) Open Access

\begin{abstract}
This paper presents the comparison of various current control strategies employed for an interleaved power factor correction (PFC) boost converter for improving the power quality. The major control strategies discussed in this paper are: peak current control, average current control, hysteresis control, borderline current control and non-linear control. These strategies are implemented in MATLAB/SIMULINK and the performance of the proposed converter is compared under open loop and closed loop operation. From the results, the input current waveform was close to input voltage waveform implying improved power factor and reduced total harmonic distortion for nonlinear current control technique. Experimental results validate the proposed method.
\end{abstract}

\section{Keywords}

AC-DC Power Conversion, Power Factor Correction, Nonlinear Current Control, Control Techniques and Total Harmonic Distortion

\section{Introduction}

The power-electronics products are employed for a variety of applications such as power supplies for microelectronics, household electric appliances, electronic ballasts, battery charging, motor drives, power conversion circuits, etc., but this leads to rich current harmonics at the supply side. Therefore, Power Factor Correction (PFC) is necessary for AC-DC converters in order to fulfill the requirements of international standards. PFC will reduce the harmonics in the supply current and boost the efficiency of the system. Even though numerous methods have been suggested to resolve the problem of low power factor, it is important to make the supply power factor to unity. In order to meet the standards of IEC 61000-3-2 Electromagnetic compatibility (EMC): harmonic

"Corresponding author. 
current limits, achieve high power factor and reduced harmonics, power factor corrected converters are commonly employed in various types of switching power supply [1]-[3]. The continuous conduction mode (CCM) boost converter possesses many advantages such as low input current waveform distortion, high output voltage, high input power factor, less EMI noise and simple circuit construction, etc.

Interleaved boost converter is one of the most popular choices for high power factor converter. This type of converter provides an output voltage greater than the input voltage and also it operates at maximum duty ratio. The boost converter is supplied from a full wave rectified line voltage and operated so that the input current follows the input voltage and it is generally preferred because of its simple construction. Power factor correction (PFC) [4]-[8] is necessary for AC-DC converters in order to accomplish the requirements of international standards. PFC will decrease the harmonics in the supply current and raise the efficiency of the system. Even though a number of methods have been recommended to resolve the problem of power factor, it is essential to make the supply power factor closer to unity. Hence power factor corrected boost converter is very attractive, which eliminates the filter from input side thereby achieving ripple free power in the AC line. Boost converter generally has at least two semiconductors and one energy storage element, a capacitor, inductor, or the two in combination. Filters made of capacitors or in combination with inductors are normally added to the output of the converter which makes the circuit bulky. Hence to overcome this interleaved boost converters were suggested. Due to the absence of filter at supply side the converter is not bulky and hence it increases the power density of the converter. The above said is achieved by employing a coupled inductor [9] [10]. As power densities continue to rise, interleaved boost designs become a powerful tool to keep input currents manageable and increase efficiency, while still maintaining good power density. With mandates on energy savings more common, interleaved construction may be the only way to achieve design objectives. The benefits of this approach are demonstrated by a two-phase boost converter design. A modified interleaved boost converter with a coupled inductor is also called as ripple steering technique which is also identified as coupled magnetic filters technique [11].

Various techniques are available for shaping the line current, and also they are supported by integrated circuits [12]-[14]. These closed loop current control techniques provides very low current harmonic distortion, good performance, simple circuit construction and high efficiency. Therefore the shape of the current waveform is determined and found to be in line with the supply voltage waveform. The current control techniques offer improved performance and low input THD over existing open loop PFC [15] schemes. Therefore various control techniques such as peak current control, average current control, hysteresis control, borderline control and nonlinear current control for interleaved boost converter have been studied and analyzed. These techniques are simulated in MATLAB/SIMULINK and the feasibility of the proposed topology is experimentally verified. The objective of this paper is to improve the power factor of the proposed interleaved boost PFC converter.

The paper is organized as follows: Section 2.1 gives a brief idea of the interleaved boost converter. Section 2.2 analyzes the effect of the ripple steering technique in detail. Section 3 deals about the design of interleaved boost converter. Section 4 analyzes the operation of interleaved boost PFC converter with different current control strategies. Section 5 gives the comparison between the proposed control techniques and the open loop configuration of interleaved boost PFC with ripple steering technique. The analysis is made in terms of input current, input voltage, output voltage and total harmonic distortion with the help of simulation results. A prototype has been built and tested, and the experimental results are presented in Section 6.

\section{Theoretical and Experimental Methods}

\subsection{Interleaved Boost Converter}

Power factor correction (PFC) interleaved boost converter is a popular topology for high level switching power supply to improve the power factor (PF). An interleaved boost converter provides benefits of component availability, high efficiency, high power density and low harmonics compared to conventional converters. Hence it has been extensively used in numerous applications. The important features for these type of converters is the current cancellation effect thereby reduces the size, weight and cost of the filters. It also identifies the differential mode EMI noise hence suitable for input filter design, input and output side capacitor selection.

The interleaved boost converter is simply two traditional boost converters with half the power rating as a result the input bridge rectifier must have the same power rating as the conventional power factor corrected boost converter. And also design equations will be alike to that of conventional converters. Interleaved boost converters are usually employed for high input-current and high input to output voltage conversion applications. The 
added benefit of interleaving is that ripple currents are reduced at both input and output side. There is an increased efficiency by splitting the output current into " $\mathrm{n}$ " pathways; considerably it reduces the power and inductor losses. Here the interleaved structure is presented for boost converter to improve the efficiency of the PFC converter [16]-[18]. This is mainly done for the applications of DC voltage smaller than the AC-side voltage.

\subsection{Interleaved Boost Converter with Ripple Steering Technique}

Interleaved boost converter with ripple steering technique is employed to achieve active power-factor correction. This ripple steering technique is also called as coupled magnetic filter technique and it is implemented to IBC topology in this paper. The concept of zero-ripple or ripple-free input current is not new. It was originally used to reduce weight and increase power density of the converter. Generally, a zero-ripple phenomenon is achieved by using the coupled inductor technique in a modified boost converter. Based on the zero-ripple input current concept, various PFC converters with separate inductors and EMI filter requirements can be found in the literature [19]-[22]. As earlier studied, a modified boost converter with a coupled inductor can provide a smaller converter size compared with conventional boost converter. The application of the zero-ripple current phenomenon is of significant importance in switching converters, where there are few reasons why it is necessary to minimize inductor ripple currents. It reduces the stress on converter capacitors, resulting in either minimum power loss or more comfortable filtering requirements. And also most of the converter topologies have a pulsating current at input or output, or at both. Advantages of interleaving, such as higher efficiency, reduced input and output ripple and also inductor count and the switches count are reduced. The conventional inductor is replaced by a coupled inductor and a blocking capacitor here. Importance is given to the application of ripple steering to power factor corrected boost converter. Figure 1 shows the proposed PFC boost converter with a coupled inductor and a blocking capacitor. There is a fall in noise, size and complexity of filters by adapting the proposed technique. Although the control technique is similar to that of a conventional converter, there is some variation in power stage transfer function. This is done by replacing the inductor in a conventional boost converter by a coupled inductor and a blocking capacitor. Figure 1 shows the modified boost converter with ripple steering technique.

\section{Design Equation for IBC}

Designing an interleaved boost converter includes the following steps:

\subsection{Choice of Duty Ratio}

Since the number of phases chosen in this paper is two, $50 \%$ of the duty cycle will be the best choice. And also $D=0.5$ gives less ripples when compared to other duty ratios. The duty ratio is calculated as,

$$
D=\frac{V_{o}-V_{i n}}{V_{o}}
$$

where, $V_{o}$ denotes the output voltage in volts, $V_{i n}$ denotes the input voltage in volts and $D$ denotes the duty ratio.

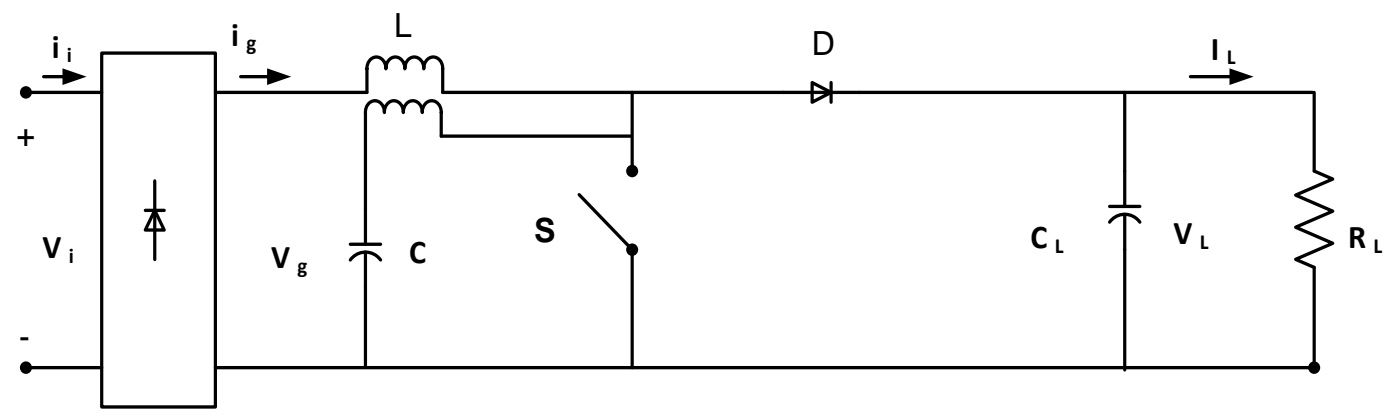

Figure 1. Interleaved boost converter with ripple steering technique. 


\subsection{Optimal Number of Phases}

This paper uses two phases, as the number of phases is increased the ripples will be minimum. But increasing the number of phases will increase the cost and complexity of the circuit. Therefore the number of phases is chosen as two.

\subsection{Design of Inductance and Capacitance}

The inductor and capacitor values can be found using the formula given below.

$$
C=\frac{V_{o} D T}{R \Delta V_{o}}
$$

where, $V_{o}$ denotes the output voltage in volts, $D$ denotes the duty ratio, $R$ denotes resistance in $\Omega, T$ denotes the switching period in seconds and $\Delta V_{o}$ denotes the change in the output voltage.

$$
L=\frac{V_{s} D}{\Delta i_{L} F}
$$

where $V_{s}$ denotes the source voltage in volts, $D$ denotes the duty ratio, $F$ denotes the frequency in hertz and $\Delta i_{L}$ denotes the inductor current ripple in ampere.

\section{Current Control Strategies for Interleaved Boost Converter with Ripple Steering Technique}

The main objective of this paper is to present the current control design techniques and experimental results for the proposed converter. An open loop control technique is often used in simple processes because of its simplicity and low cost, especially in systems where feedback is not significant. Generally, to obtain a more accurate control of the circuits, closed loop systems are designed to automatically achieve and maintain the desired output condition by comparing it with the actual condition. It does this by generating an error signal which is the difference between the output and the reference input. By adopting current control techniques [23], the power factor obtained in the open loop configuration of the converter can be enhanced. The advantage of current control techniques over voltage control techniques are, it provides an additional inner control loop control. The inductor current is sensed and used to control the duty cycle. An error signal is generated by comparing output voltage with reference voltage. Then this error signal is used to generate control signal. The inductor current is then sensed and compared with control signal to generate the duty cycle of the switch and drive the switch of the converter. If the feedback loop is closed, the inductor current becomes proportional with control signal and the output voltage becomes equal to reference voltage. Using the feedback and feed forward loops, lower harmonic profile can be maintained. The general control principle of the controller is that the supply current is forced to track a generated sinusoidal reference so that the converter draws a sinusoidal current; thereby improving the power factor. Many current control strategies have been reported in the literature. The classification of current control strategies namely discontinuous inductor current mode (DICM) where the inductor current reaches zero during a cycle and continuous inductor current mode (CICM) where the inductor current does not reach zero during a cycle and energy is stored in the inductor. To operate the converter as a power factor corrector, consider continuous conduction mode: as the current stress and current ripple are minimum in this mode [24]-[26]. A number of continuous inductor current mode control strategies such as peak current control, average current control, hysteresis current control, borderline current control and non-linear control are implemented and analyzed for the proposed converter.

\subsection{Peak Current Control}

A schematic circuit diagram of PFC interleaved boost converter under peak current control [27] is presented in Figure 2. The switch turns on with a constant frequency and it can turn off until inductor current reaches a level set by the outer loop. Therefore, instant over-current switch protection is easier, but there is very noise sensitive control. A compensating ramp is always required to add, when the duty cycle exceeds 0.5 , otherwise the control is inherently unstable. The switch is getting turned on with a fixed frequency by a clock signal and is turned off 


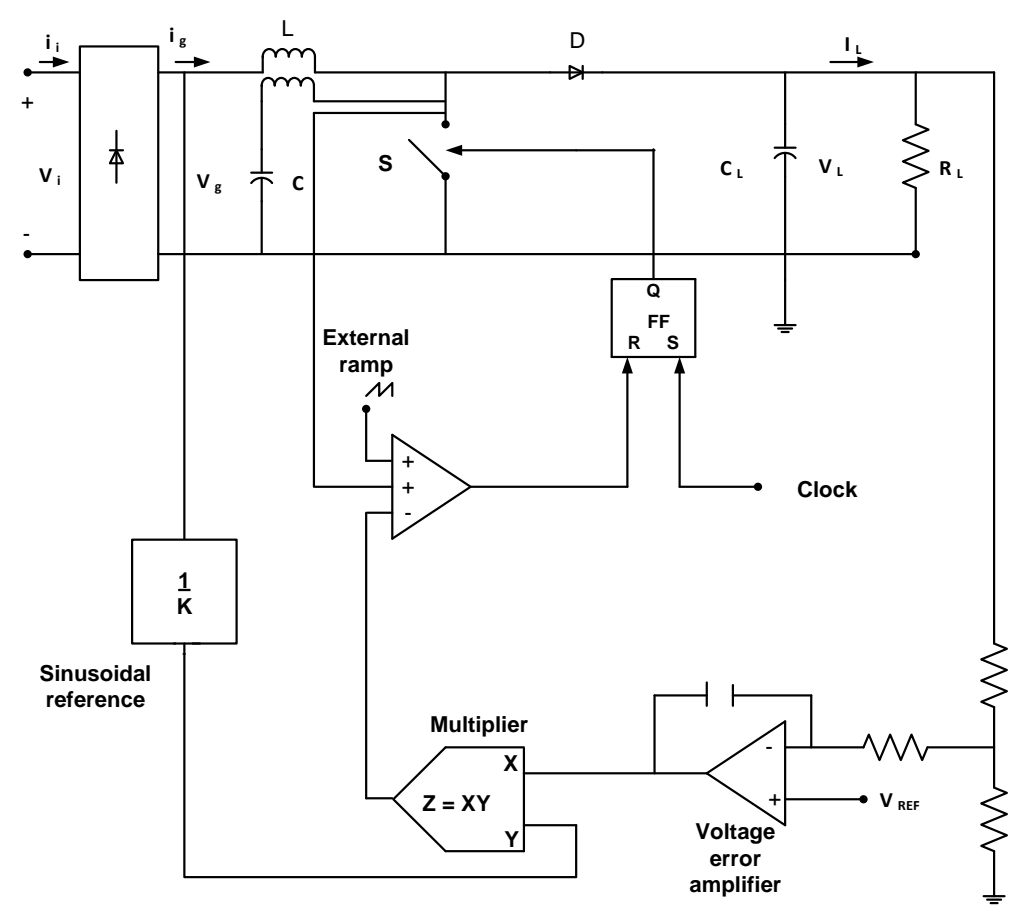

Figure 2. Control circuit for peak current control.

when the sum of the positive ramp of the inductor current (i.e. the switch current) and an external ramp (i.e. compensating ramp) touches the sinusoidal current reference. Usually, this reference can be attained by multiplying a scaled replica of the rectified line voltage $v_{g}$ times the output of the voltage error amplifier, which sets the current reference amplitude. In this way, the reference signal is naturally synchronized and always proportional to the line voltage, which is the condition to obtain unity power factor. Whenever the inductor current crosses zero, switch is turned $\mathrm{ON}$ and as it reaches the reference current, the flip-flop is reset and the switch is turned OFF. Obviously the ramp compensation can improve the quality of the input line current, which means the amplitude of the ripple is decreased significantly. Owing to the large output capacitance, the output voltage ripple can be neglected. Therefore, the time-varying mathematical mode of PFC boost converter can be expressed as a first order differential equation as follows:

$$
\begin{gathered}
\frac{\mathrm{d} i_{L}}{\mathrm{~d} t}=\frac{\left|V_{\text {in }}(t)\right|}{L}, t \in\left[t_{n}, t_{n}+D_{n} T\right] \\
V_{\text {in }}(t)=\sqrt{2} V_{\text {in }} \sin (\omega t)=\sqrt{2} V_{\text {in }} \sin \left(\frac{2 \pi}{T_{0}} t\right) \\
\frac{\mathrm{d} i_{L}}{\mathrm{~d} t}=\frac{V_{o}-\left|V_{\text {in }}(t)\right|}{L}, t \in\left[t_{n}+D_{n} T, t_{n}+T\right]
\end{gathered}
$$

where $i_{L}$ is the inductor current, $V_{\text {in }}$ denotes the root mean square value of the line voltage.

$V_{o}$ is the DC output voltage, $T$ is the switching cycle and $D$ is the duty cycle.

\subsection{Average Current Control}

In most of the power electronic converter applications the output variable is the voltage and is involved in the outer loop. The variable within the inner loop is current, this is the reason this technique is called as average current control technique. The average current controlled interleaved boost PFC converter, is designed to operate in CCM, it may transit to DCM when the load becomes light. Figure 3 shows the main circuit and control block diagram of the average current controlled converter. It uses voltage control loop and current control loop. 


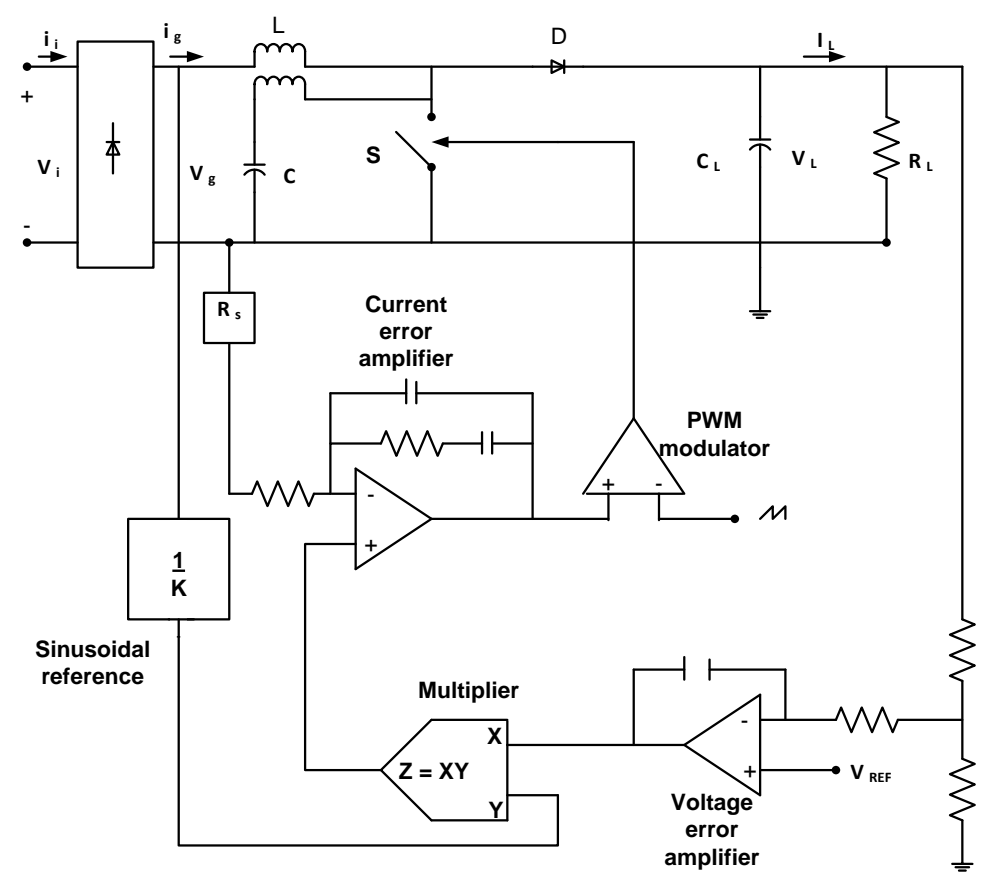

Figure 3. Control circuit for average current control.

Firstly the inductor current is sensed and filtered by a current error amplifier whose output drives a PWM modulator. Hence the inner current loop tends to limit the error among the average input current $i_{g}$ and the reference. The converter works in CICM, so the same considerations done with regard to the peak current control can be applied. The average of inductor current is taken as reference and the inductor current is forced to go after it. The switch is turned ON whenever the inductor current reaches zero and switch is turned OFF when the inductor current falls below the reference.

We know that the rectified input voltage of the boost converter can be expressed as follows:

$$
v(t)=\left|v_{\text {in }}(t)\right|=\sqrt{2} V_{\text {in }}\left|\sin \omega_{\text {in }} t\right|
$$

where $v_{i n}$ is the input voltage, $V_{i n}$ and $\omega_{i n}$ are the root mean square value and angular frequency of the input voltage respectively.

The average value of the inductor current is programmed to sinusoidal shape for achieving the PFC function. Under different input voltage and load conditions, the average current controlled technique may operate in all CCM or partly CCM/DCM. When the converter operates in CCM, the duty cycle $D_{C C M}$ and peak-to-peak value of the inductor current ripple $\Delta i$ are expressed as follows:

$$
\begin{array}{r}
D_{C C M}(t)=1-v_{g}(t) / V_{o} \\
\Delta i(t)=\frac{v_{g}(t) D_{C C M}(t)}{L_{b} f_{s}}
\end{array}
$$

where $f_{s}$ is the switching frequency.

\subsection{Hysteresis Control}

Figure 4 shows an alternative control technique called hysteresis control, which is proposed and analyzed [28]. Among the various control methods, hysteresis current control is the extensively used technique owing to its noncomplex implementation, enhanced system stability, fast response, less distortion in input current waveform and regulating the output voltage. This technique is believed to exhibit greater stability. According to this control technique, when the inductance current is less than the lower current reference, power switch is turned ON 


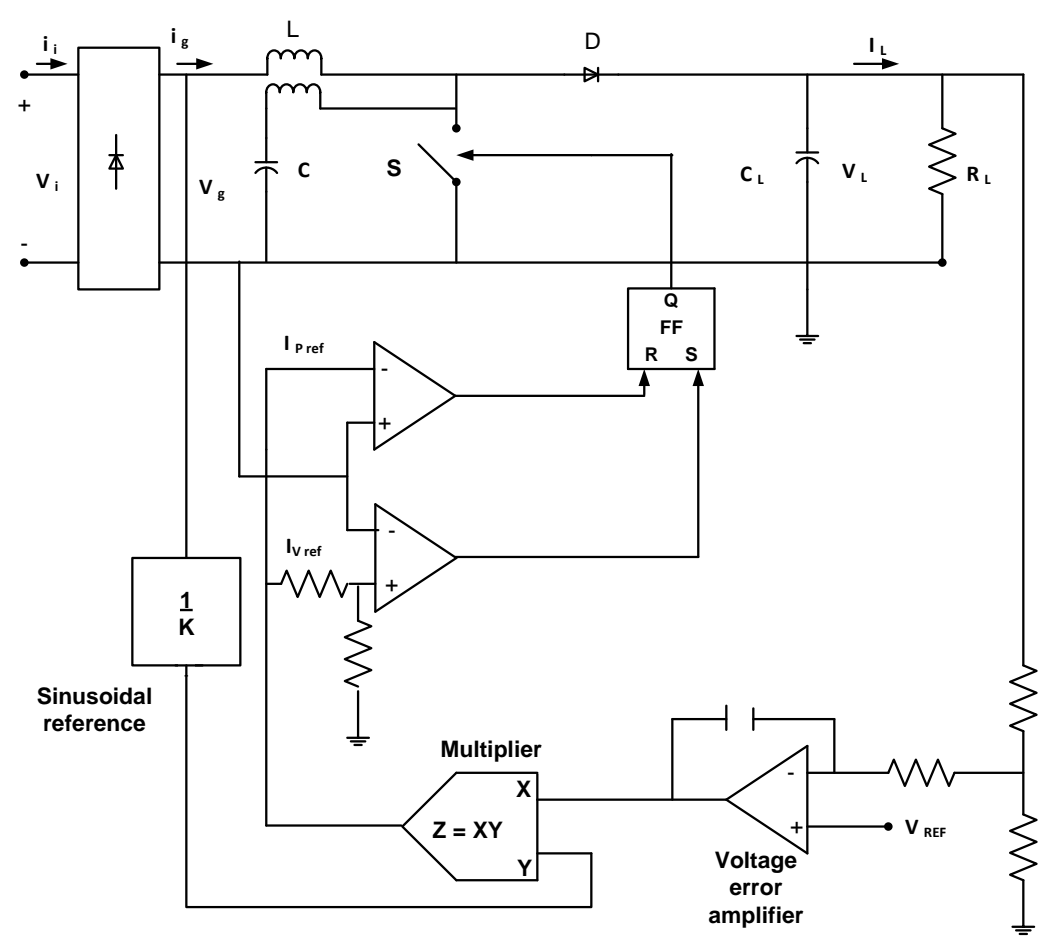

Figure 4. Control circuit for hysteresis control.

and when the inductance current is more than the upper current reference, power switch is turned OFF. The boost converter is being operated at continuous current mode (CCM). For the hysteresis control, the inductance current is switching at a variable switching frequency. The switch must be turned ON while zero crossing of the line voltage for restraining very high switching frequency. In order to avoid too high switching frequency, the switch can be kept open near the zero crossing of the line voltage so introducing dead times in the line current.

\subsection{Borderline Control}

In this type of control approach the ON time of the switch will remain constant during the line cycle and the switch is turned ON when the inductor current falls to zero. Therefore the converter operates at the boundary between Continuous and Discontinuous Inductor Current Mode. The freewheeling diode is turned OFF softly and the switch is turned ON at zero current. So the commutation losses are also reduced. And also the higher current peak increase the device stresses and conduction losses will lead to heavier input filters. This is a type of hysteretic control in which the lower reference $I_{V}$, ref is zero anywhere. The principle scheme is shown in Figure 5 . The instant input current is constituted by a sequence of triangles whose peaks are proportional to the line voltage. Thus, the average input current becomes proportional to the line voltage, this characterizes this control as an automatic current shaper technique. Some of the merits of this technique are: compensation ramp is not necessary, no need of a current error amplifier and switch current limitation can be introduced.

\subsection{Nonlinear Carrier Control}

Nonlinear carrier controllers are proposed for high power factor boost rectifiers with low total harmonic distortion [29]. In this type of controllers, the duty ratio is determined by comparing a signal derived from the main switch current with a periodic nonlinear carrier waveform. As a result, the average input current follows the input line voltage. This technique is suitable for boost converters operating in the continuous conduction mode. The proposed controller obtains the duty ratio in each switching period from the comparison of the negative ramp carrier waveform and the sensed inductor current signal as shown in Figure 6 and sensed switch current signal as shown in Figure 7. So, the input voltage sensor, the error amplifier in the current feedback loop, and the multiplier as used in the conventional control technique are not required. 


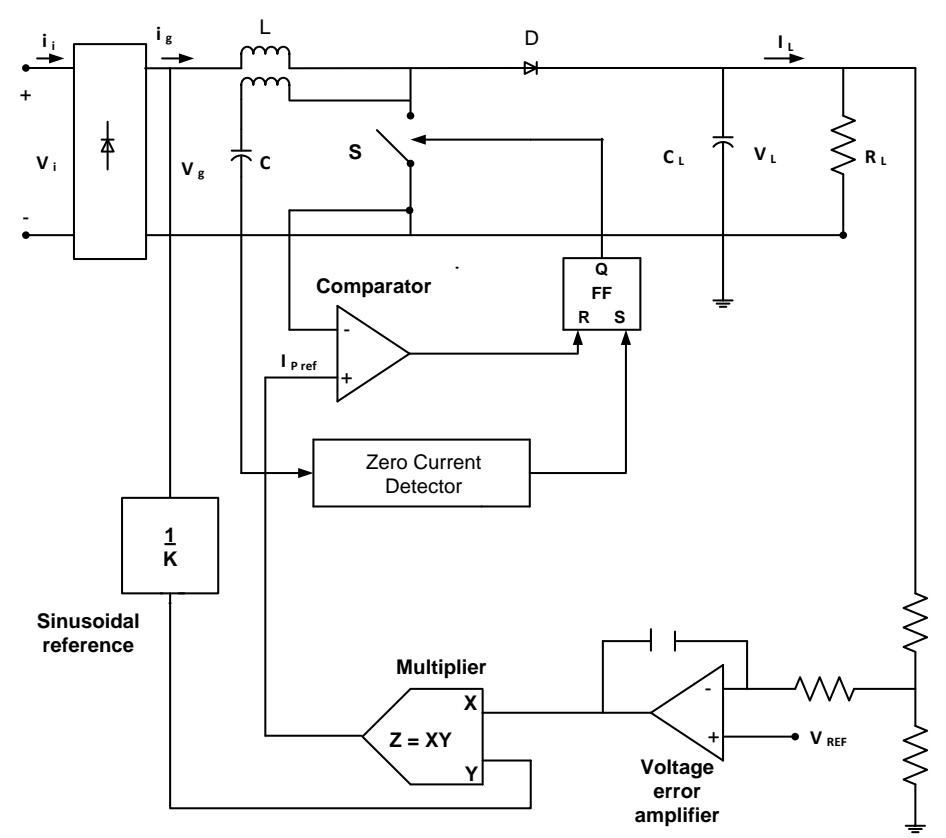

Figure 5. Control circuit for borderline control.

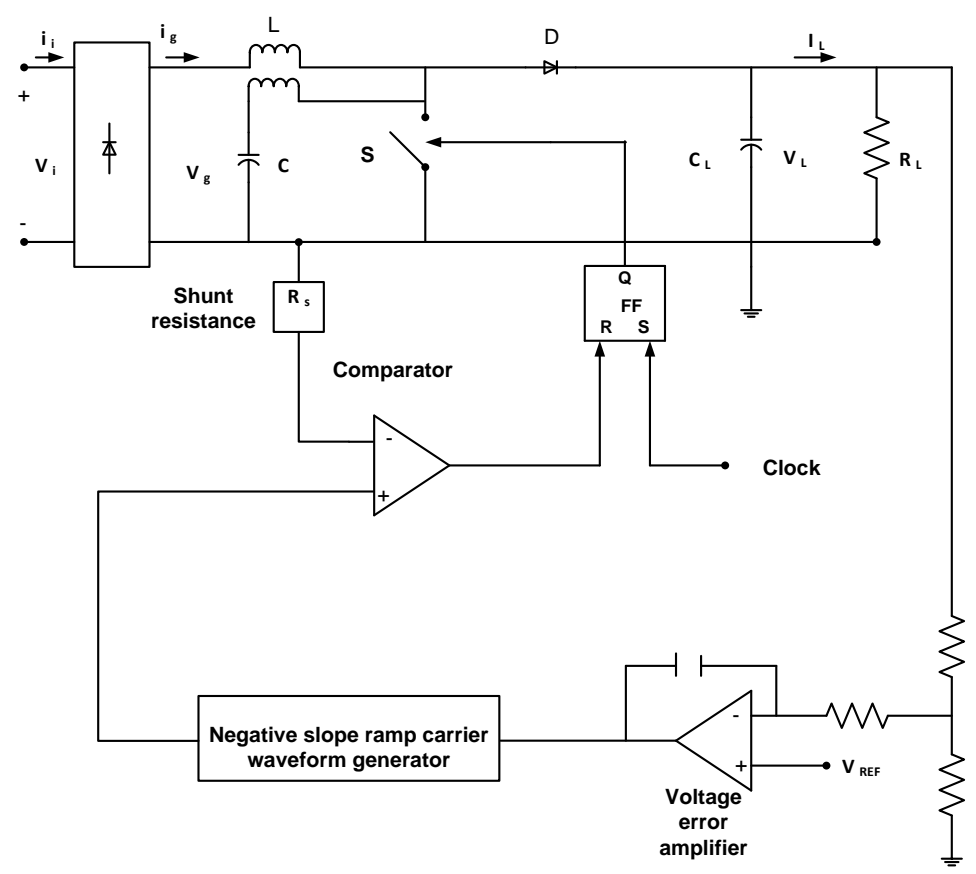

Figure 6. Control circuit for non-linear current technique-inductor current sensing.

\section{Simulation Results}

The simulation results of the different current control strategies for interleaved boost converter are discussed here. The converter is designed with the simulation parameters as shown in Table 1; The performance of the interleaved boost converter is examined by computing parameters such as Total Harmonic Distortion (THD), Distortion factor $K_{d}$, Displacement factor $K_{\theta}$ and the power factor. Two phase interleaved boost converter with ripple steering technique for different control techniques are simulated using MATLAB/SIMULINK. 


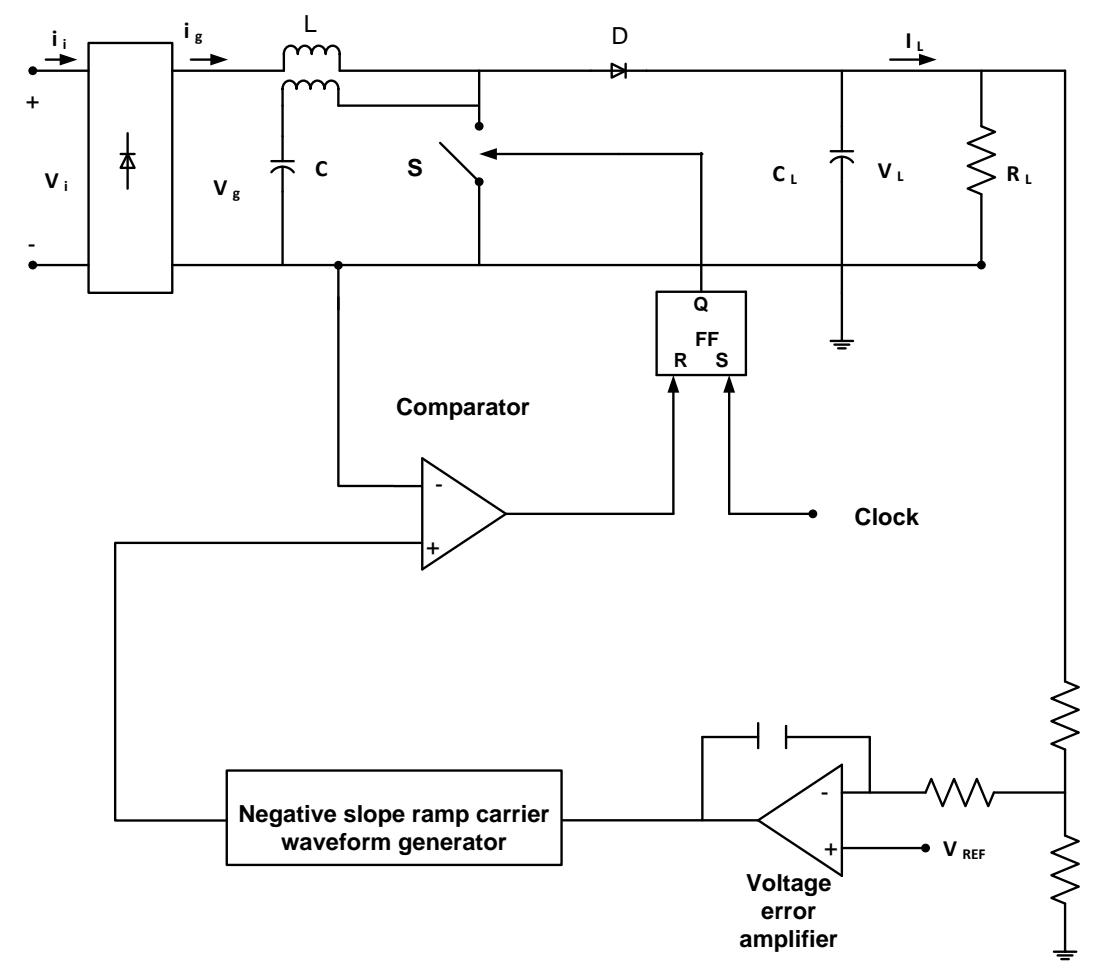

Figure 7. Control circuit for non-linear current technique-switch current sensing.

Table 1. Simulation parameters.

\begin{tabular}{cc}
\hline Parameters & Values \\
$V_{\text {in }}$ & $24 \mathrm{~V}$ \\
$V_{o}$ & $42 \mathrm{~V}$ \\
$R$ & $100 \Omega$ \\
$C$ & $400 \mu \mathrm{F}$ \\
$f_{s}$ & $50 \mathrm{KHz}$ \\
$L_{m}$ & $60 \mathrm{mH}$ \\
$D$ & 0.5 \\
\hline
\end{tabular}

For an ideal sinusoidal input voltage, the power factor can be expressed as the product of distortion factor and the displacement factor.

$$
\begin{gathered}
P F=\frac{V_{r m s} I_{1 r m s}}{V_{r m s} I_{r m s}} \cos \varphi=\frac{I_{1 r m s}}{I_{r m s}} \cos \varphi=K_{d} \cos \varphi \\
P F=K_{d} * K_{\theta}
\end{gathered}
$$

where $K_{\theta}=\cos \varphi$, which is called as displacement factor. The distortion factor $K_{d}$ is given by the following equation:

$$
K_{d}=\frac{I_{1 r m s}}{I_{r m s}}
$$

The distortion factor $K_{d}$ is the ratio of the fundamental root mean-square current $I_{1 r m s}$ to the total root 
mean square current $I_{r m s}$. The displacement factor $K_{\theta}$ is the cosine of the displacement angle $\varphi$ between the fundamental input current and the input voltage.

The following equations link total harmonic distortion to power factor:

$$
P F=\frac{\cos \varphi}{\sqrt{1+T H D^{2}}}
$$

where $\varphi$ is the angle between voltage and current, $P F$ is the power factor, THD is the total harmonic distortion.

The simulation results of the interleaved boost converter with ripple steering technique are shown in Figure 8. From Figure 8(c), it is clear that the total harmonic distortion of the proposed open loop configuration is $12.17 \%$ which is very less compared to conventional methods.

Figure 9 shows the simulation results of peak current control technique. The total harmonic distortion is found to be $11.63 \%$.

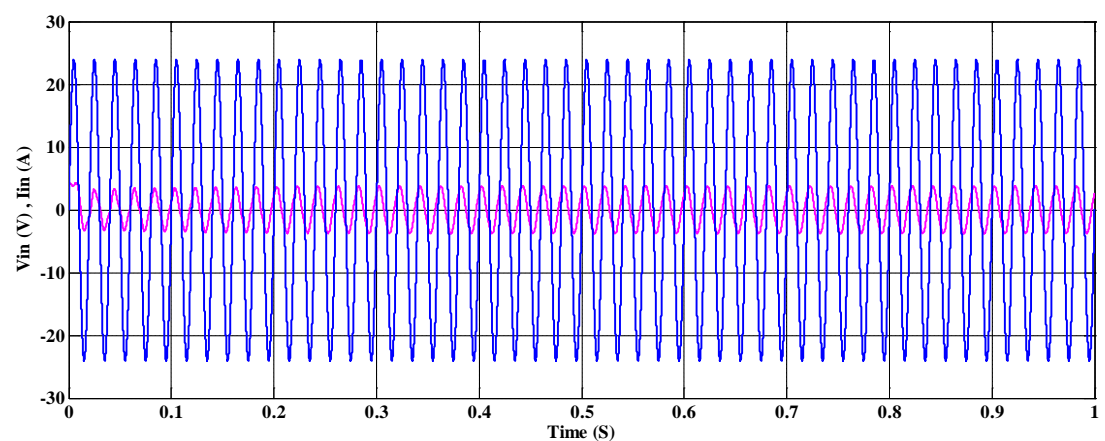

(a)

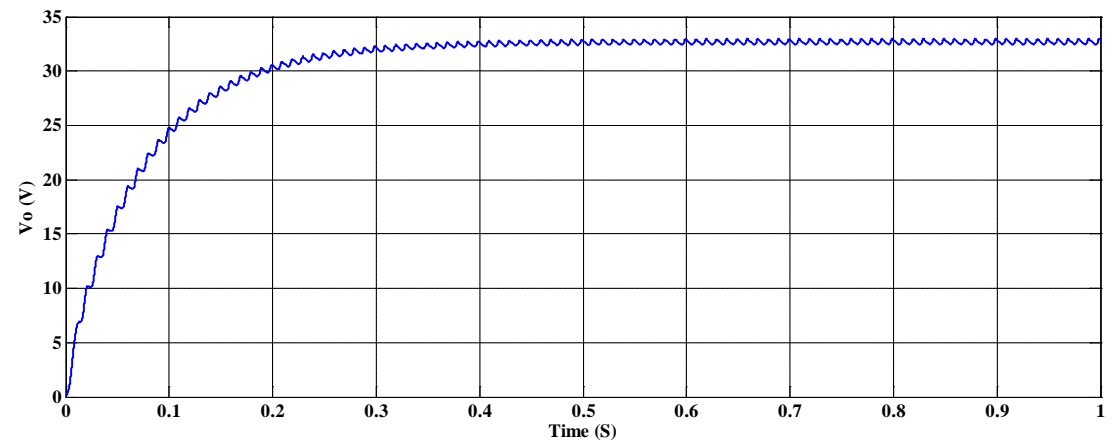

(b)

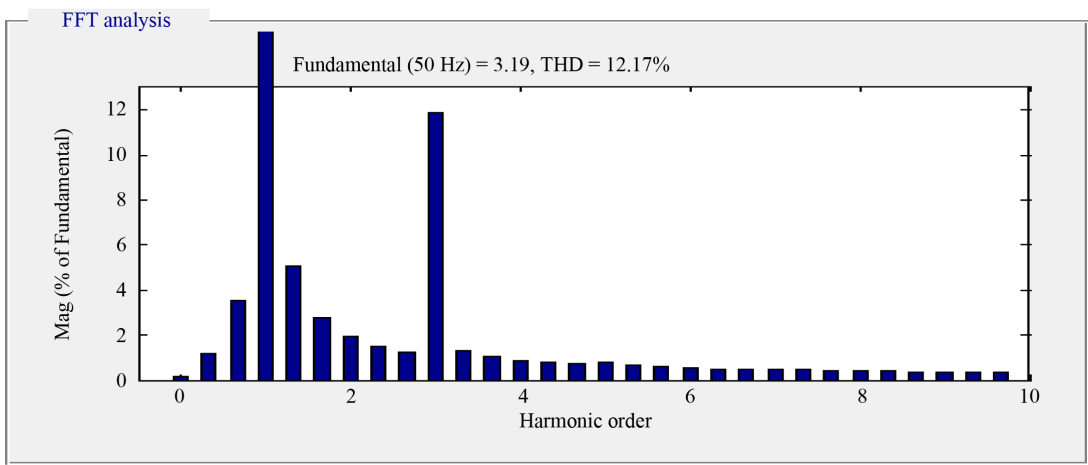

(c)

Figure 8. Simulation results of interleaved boost converter with ripple steering technique (open loop) (a) Supply voltage and supply current (b) Output Voltage (c) FFT analysis of current. 
The simulation results of the average current control technique are shown in Figure 10. From Figure 10(c), it is observed that the total harmonic distortion is $7.87 \%$ which is lower than the peak current control technique.

Simulation results of hysteresis current control technique are shown in Figure 11. From Figure 11(c), it is clear that the total harmonic distortion is quite less than the average current control method which is $4.81 \%$.

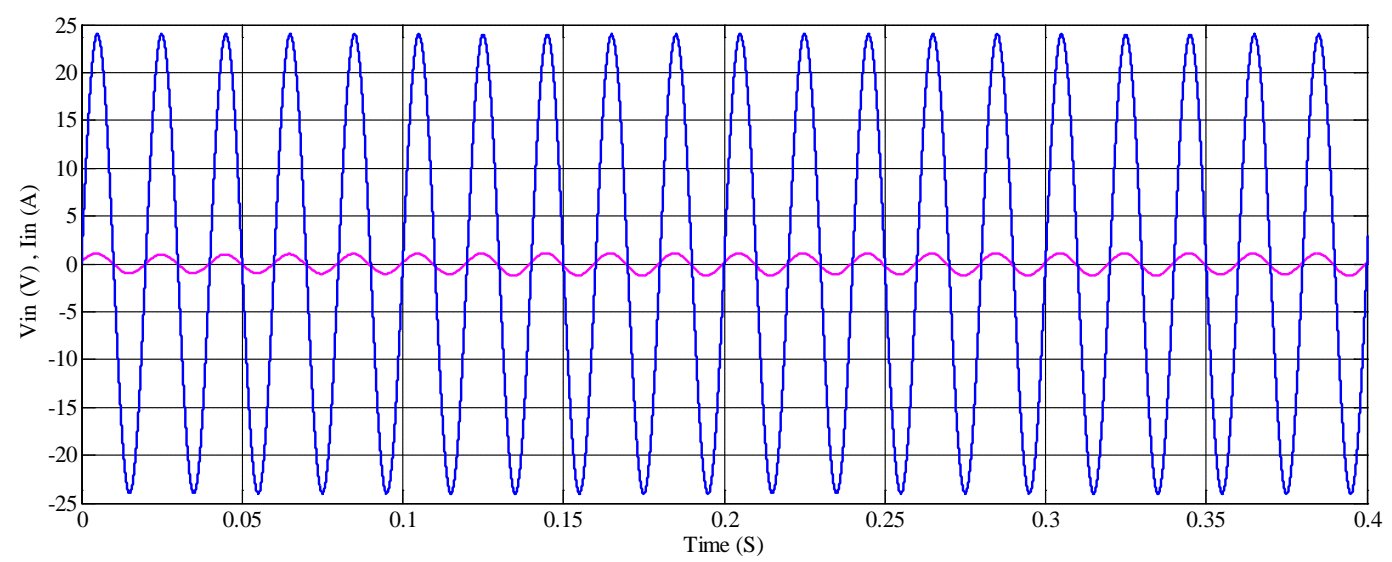

(a)

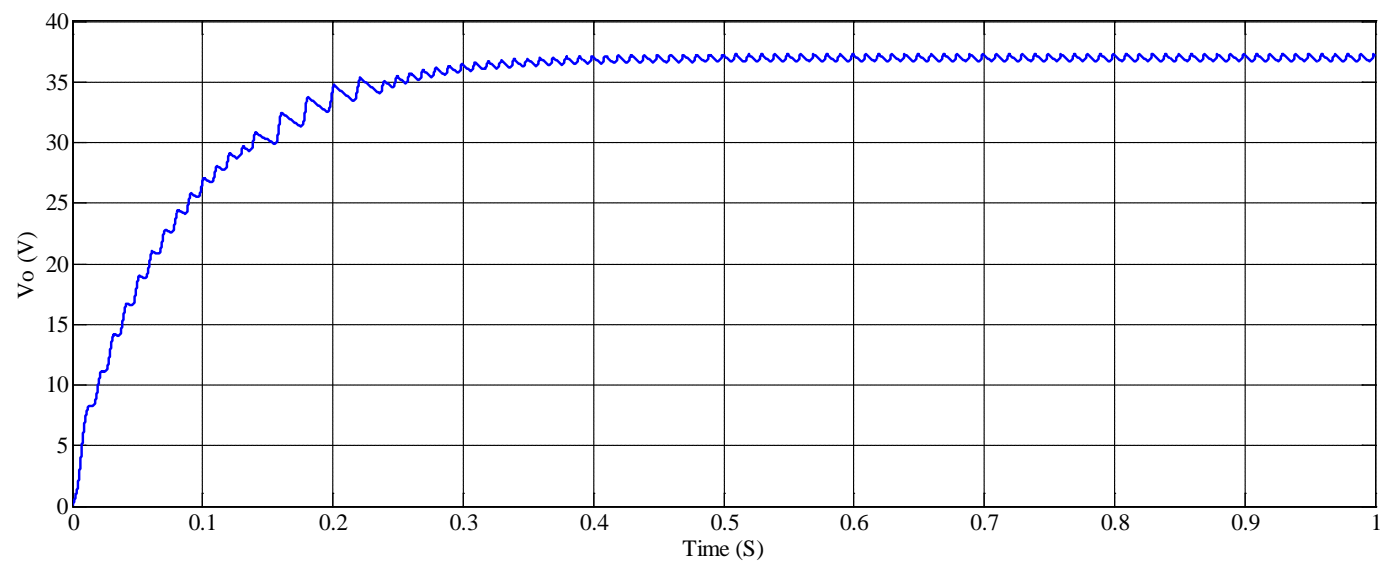

(b)

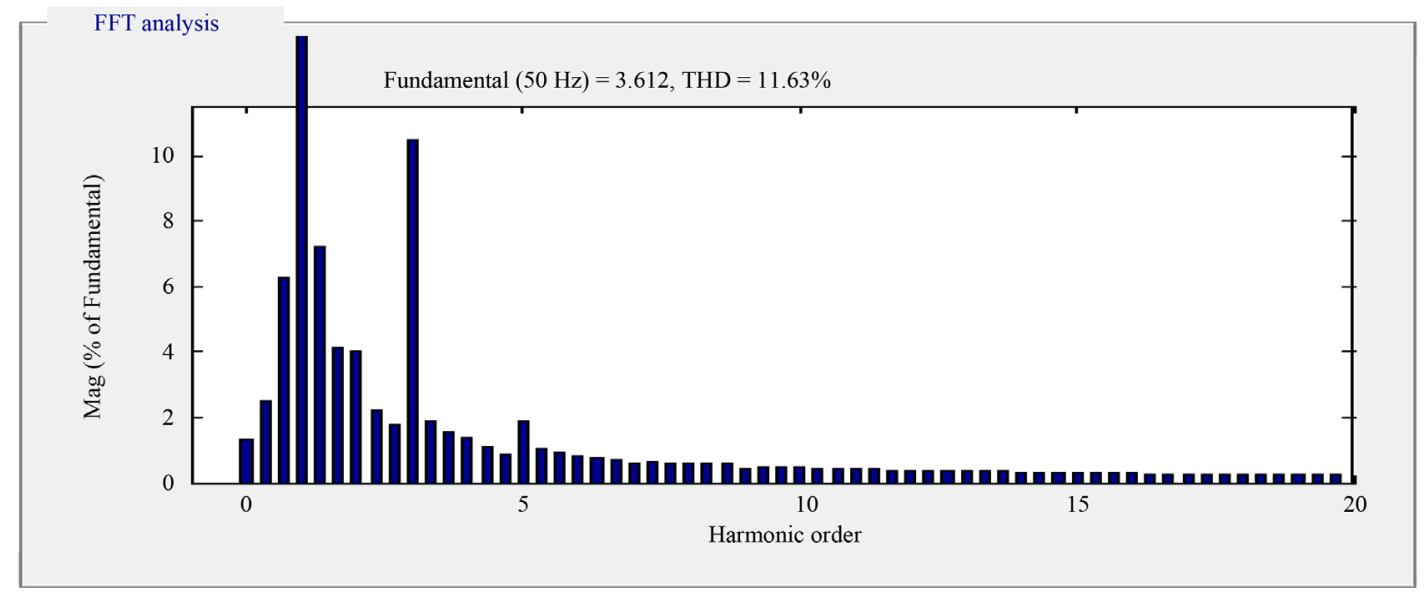

(c)

Figure 9. Simulation results of peak current control technique for interleaved boost converter. (a) Supply voltage and supply current; (b) Output Voltage; (c) FFT analysis of supply current. 


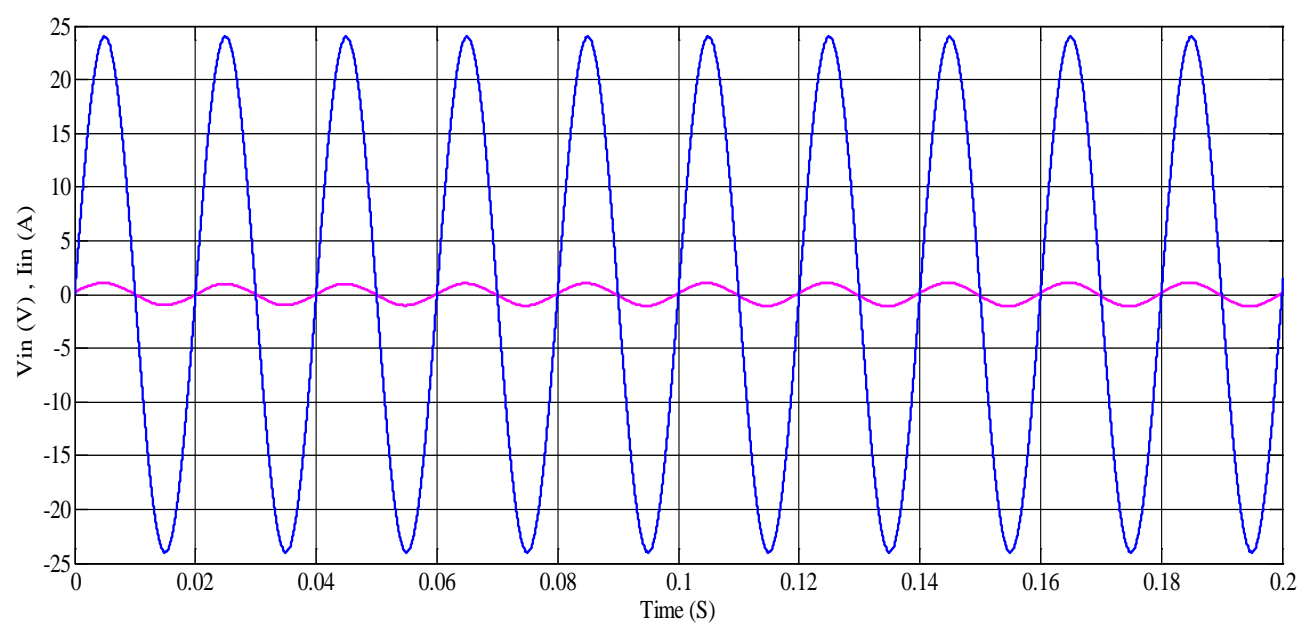

(a)

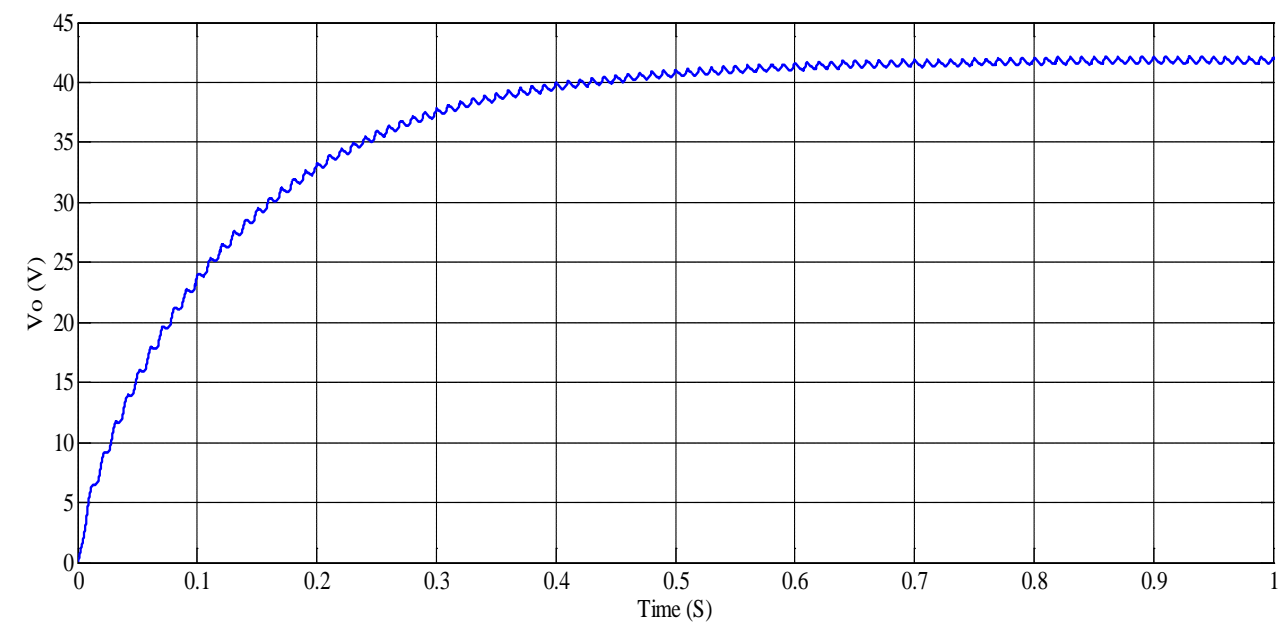

(b)

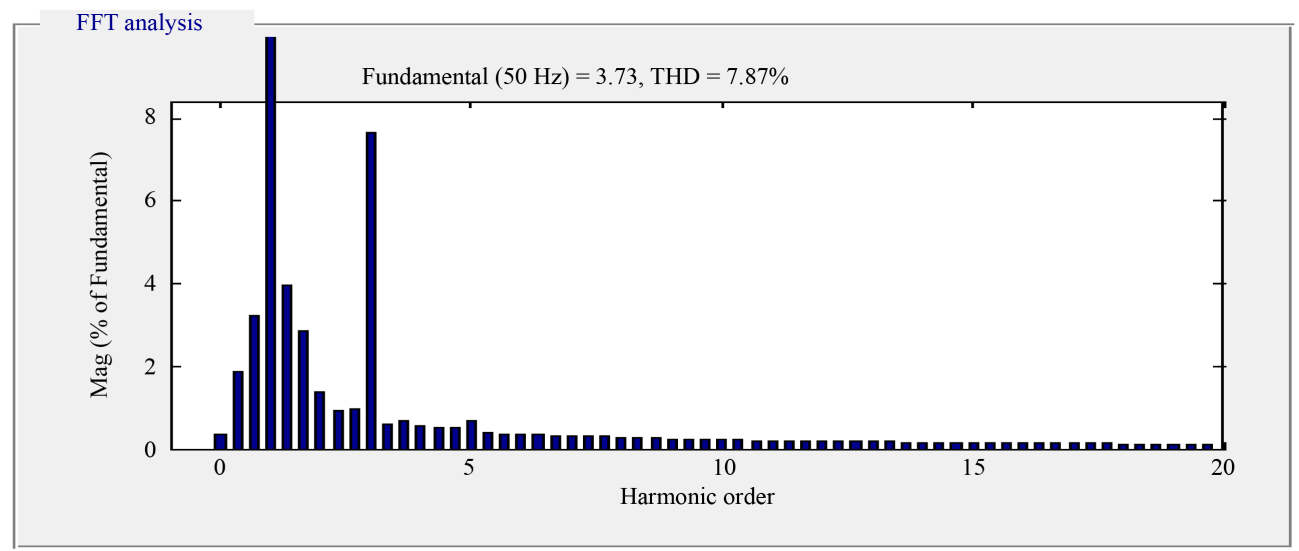

(c)

Figure 10. Simulation results of average current control technique for interleaved boost converter. (a) Supply voltage and supply current; (b) Output Voltage; (c) FFT analysis of supply current.

The simulation results of the borderline current control technique are shown in Figure 12. From Figure 12(c), it is observed that the total harmonic distortion is $3.19 \%$ which is lower than the hysteresis current control 


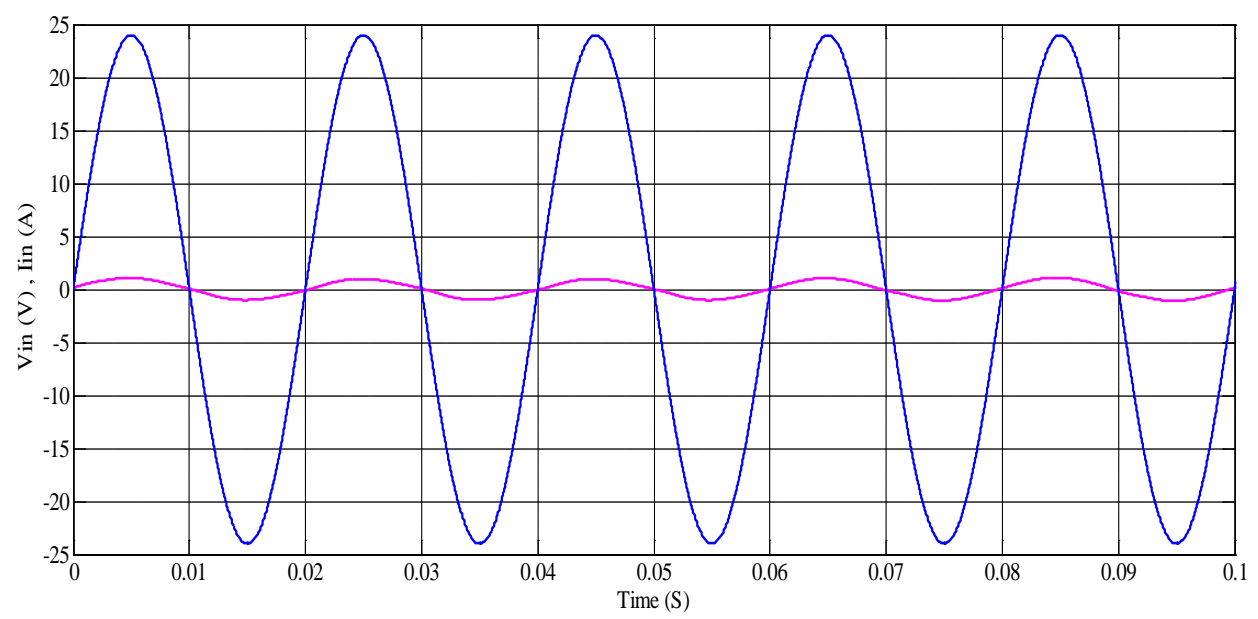

(a)

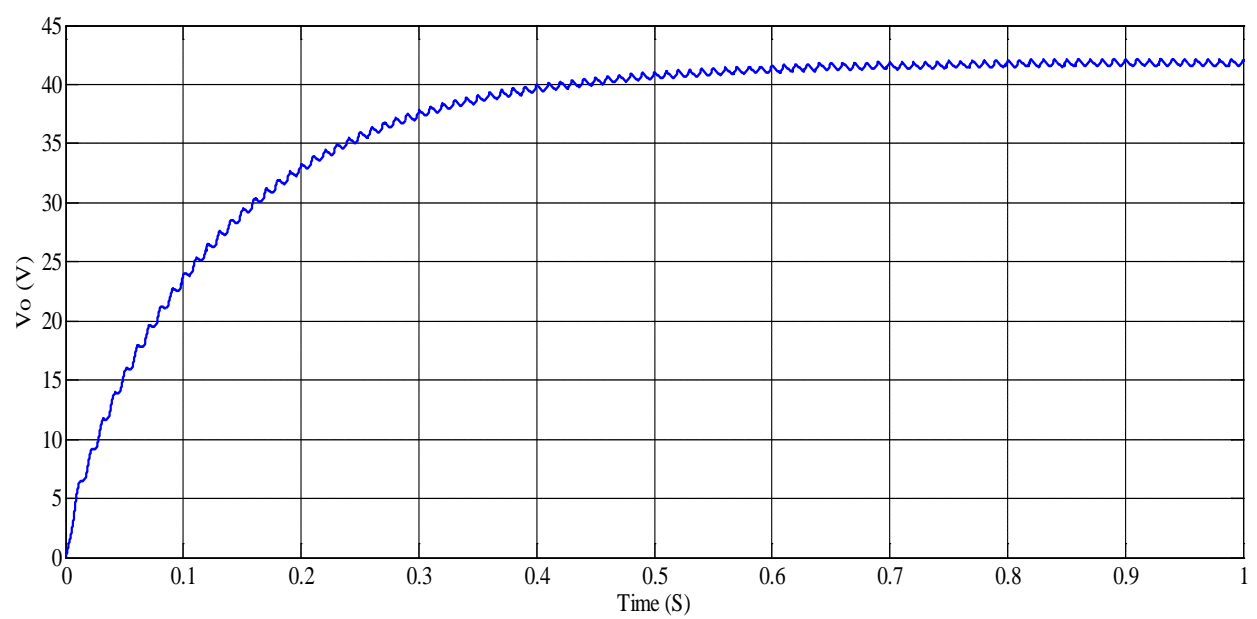

(b)

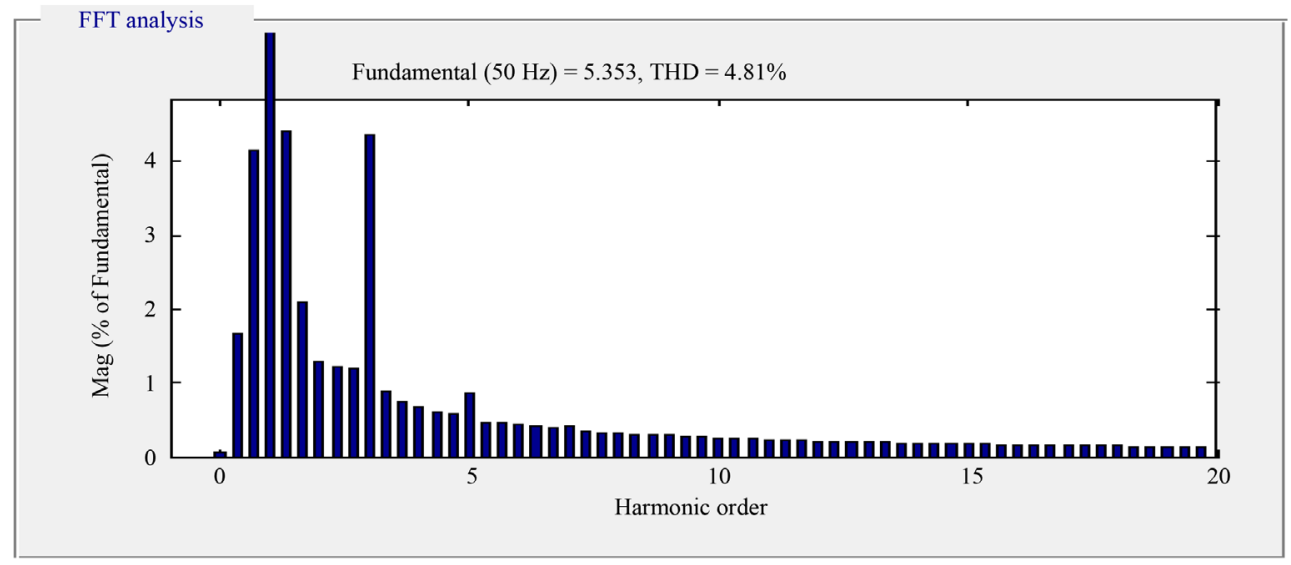

(c)

Figure 11. Simulation results of hysteresis current control technique for interleaved boost converter. (a) Supply voltage and supply current; (b) Output Voltage; (c) FFT analysis of supply current.

technique.

The simulation results of the nonlinear switch current control technique are shown in Figure 13. From 


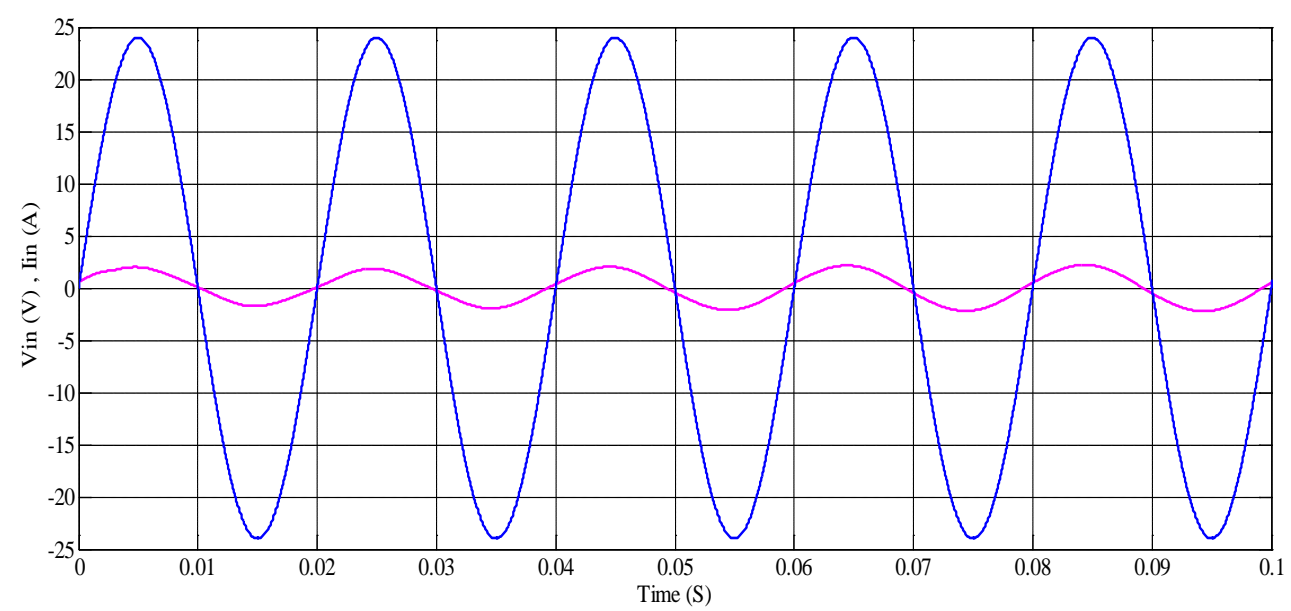

(a)

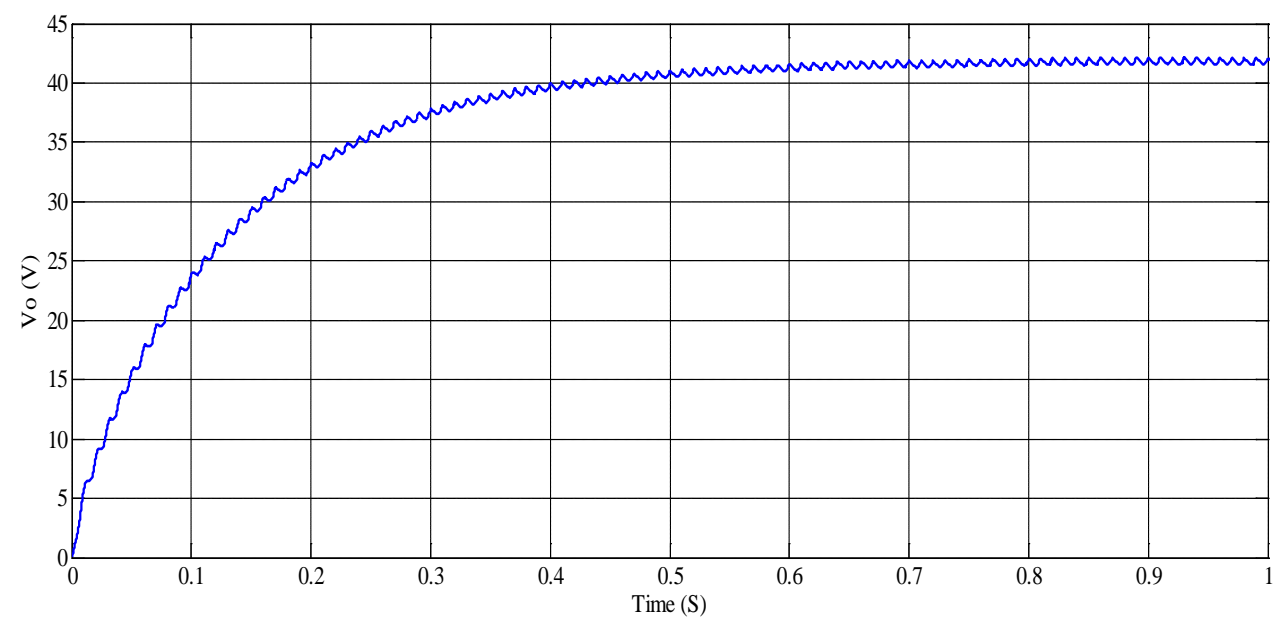

(b)

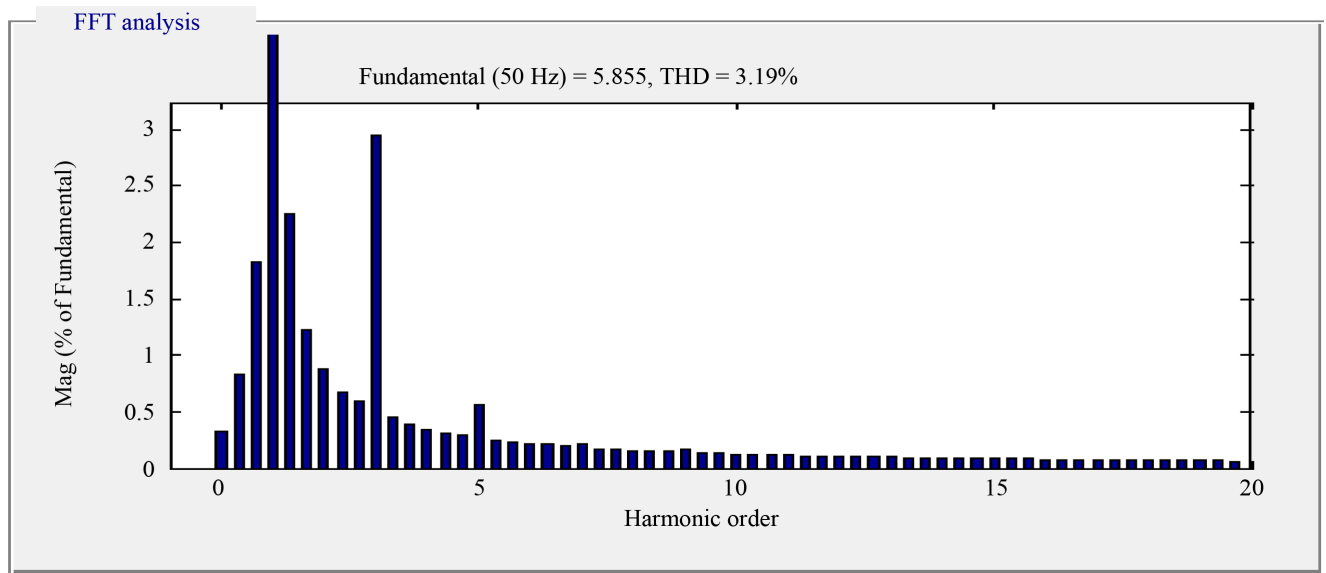

(c)

Figure 12. Simulation results of nt control technique for interleaved boost converter. (a) Supply voltage and supply current; (b) Output Voltage; (c) FFT analysis of supply current.

Figure 13(c), it is observed that the total harmonic distortion is 3.11\%.

The simulation results of the nonlinear inductor current control technique are shown in Figure 14. From 


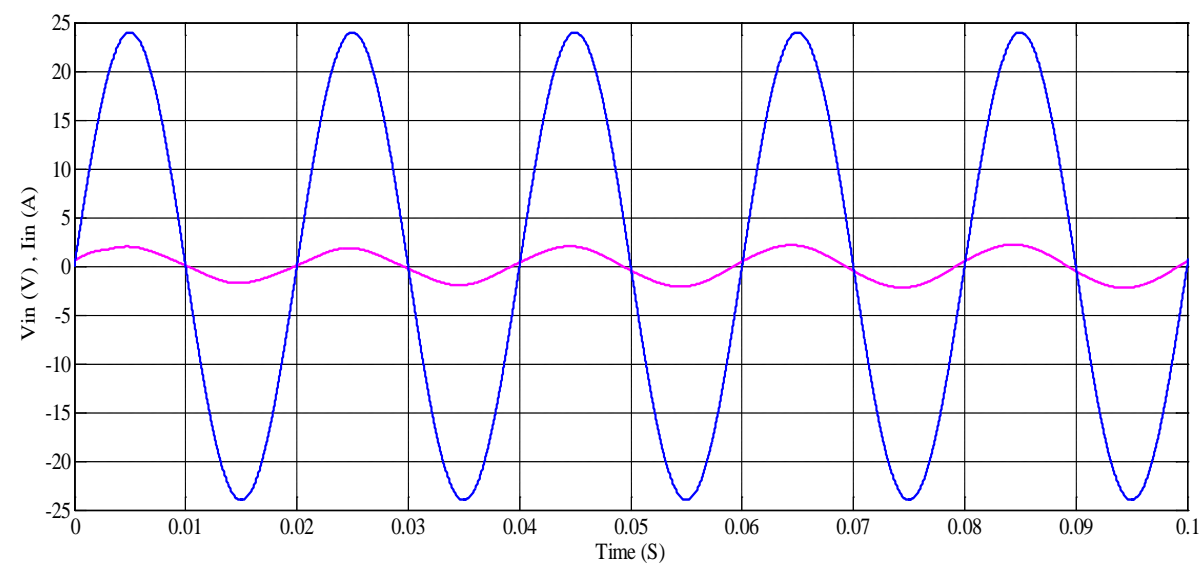

(a)

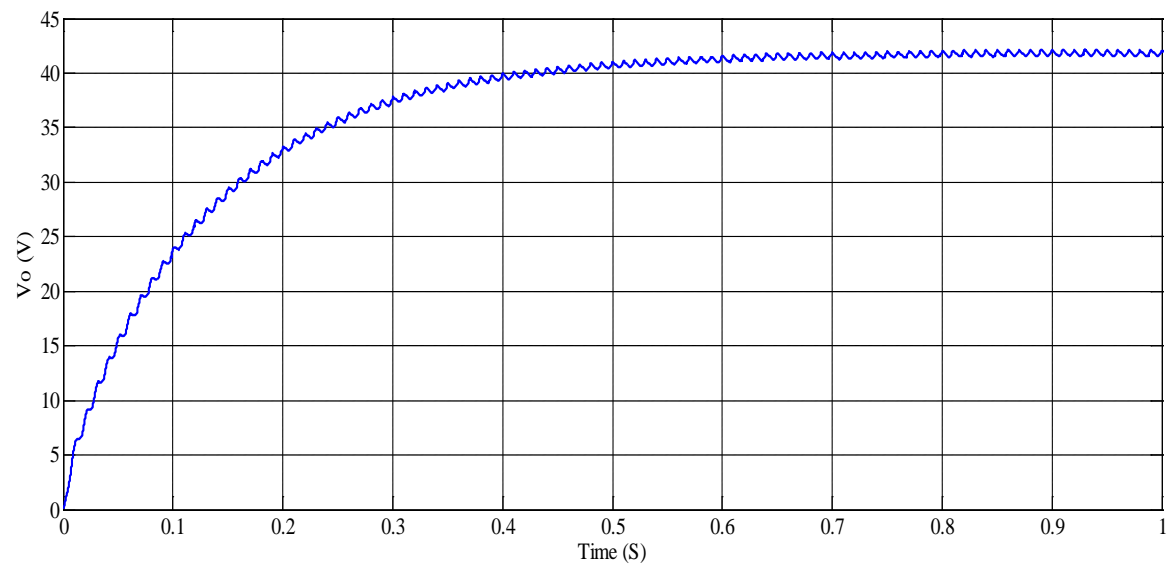

(b)

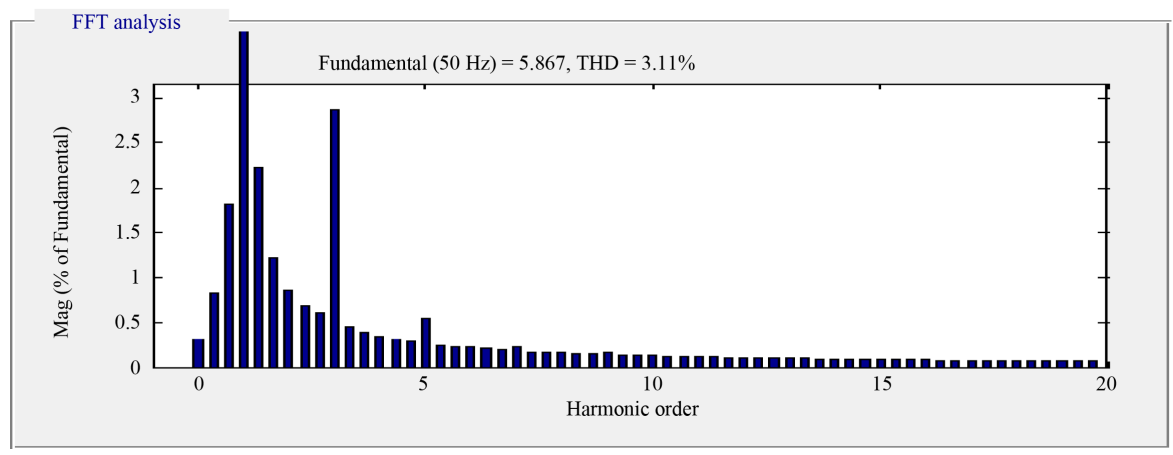

(c)

Figure 13. Simulation results of nonlinear switch current control technique for interleaved boost converter. (a) Supply voltage and supply current; (b) Output Voltage; (c) FFT analysis of supply current.

Figure 14(c), it is observed that the total harmonic distortion is $2.84 \%$.

Table 2 shows the comparison between the total harmonic distortions and supply power factor for different current control technique of an interleaved boost converter. Based on the simulation parameters, different control techniques were simulated in open loop and closed loop configuration. The obtained values of supply power factor (PF) and the total harmonic distortion (THD) are presented below.

From the above table, it is inferred that the total harmonic distortion is minimum for the nonlinear inductor 


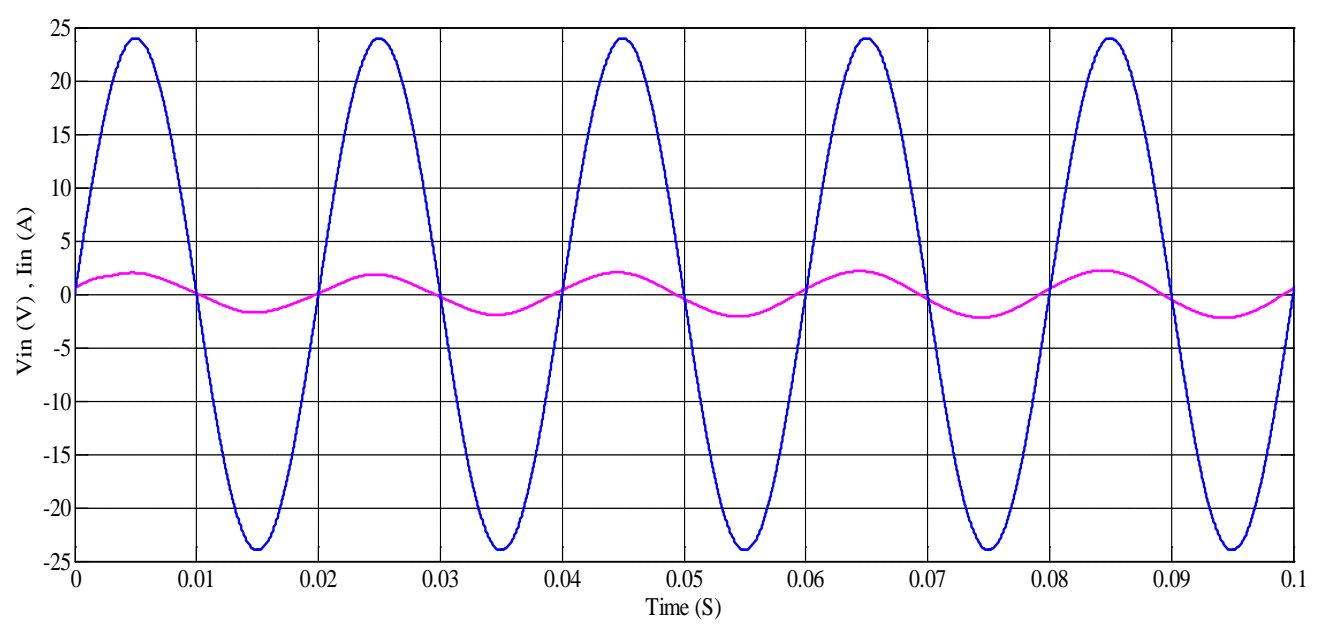

(a)

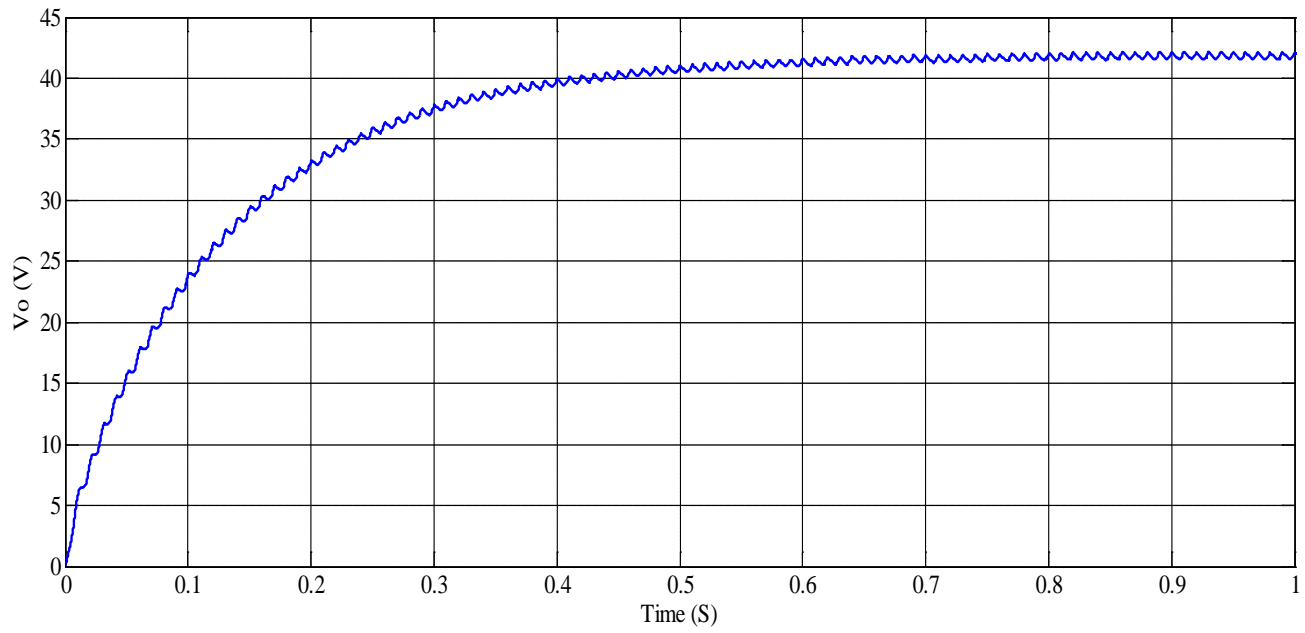

(b)

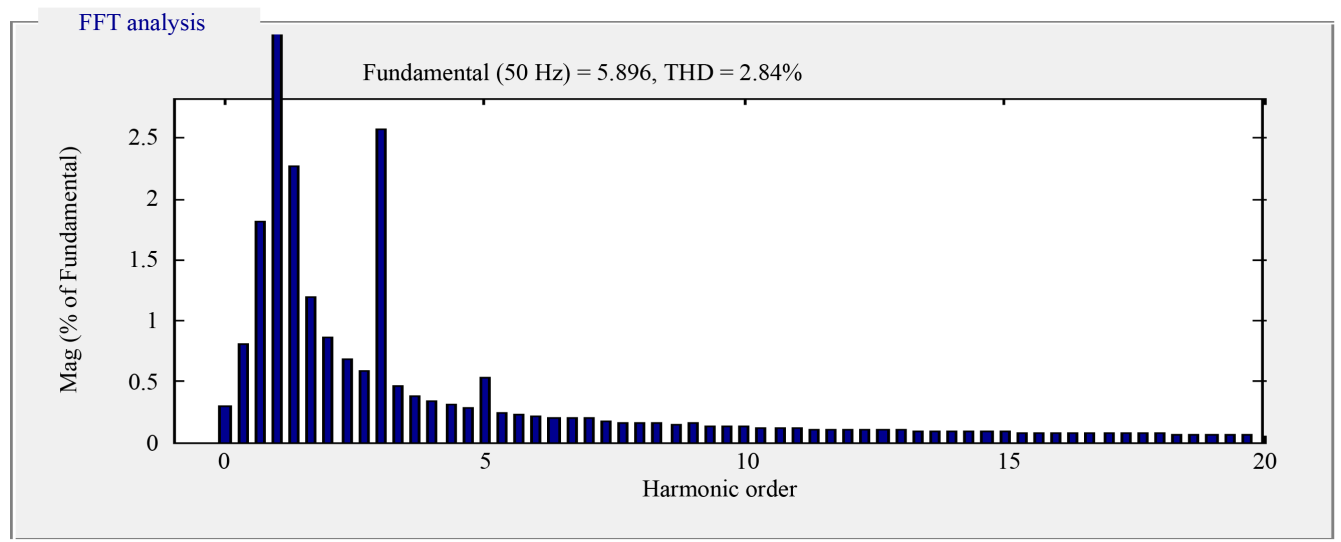

(c)

Figure 14. Simulation results of nonlinear inductor current control technique for interleaved boost converter. (a) Supply voltage and supply current; (b) Output Voltage; (c) FFT analysis of supply current.

current control technique and also it is noted that the supply power factor is closer to unity, for the proposed converter with the closed loop configuration compared to open loop configuration. 


\section{Experimental Results}

An experimental prototype was built to verify the operation of the proposed two phase interleaved boost converter with ripple steering for Non-linear current control technique. A photograph of the prototype is shown in Figure 15. The prototype is built with a power circuit, IRF840 power MOSFET which is an N channel enhancement mode MOSFET, microcontroller board and an isolation circuit. The main Features of the controller PIC16F877A are enhanced programmable Flash Memory, Self-reprogrammable under software control, Programmable code protection, Direct LED Drive Outputs, a highly-flexible and cost-effective. An optocoupler TLP250 is basically used as an isolation circuit. It prevents high voltages from affecting the system receiving the signal. An opto-isolator consists of an LED and a phototransistor together in the package.

RMS voltage, output ripple voltage and supply power factor of the proposed two-phase IBC with nonlinear inductor current technique are shown from Figures 16-18. For an input voltage of $24 \mathrm{~V}$ an output voltage of 33 $\mathrm{V}$ is obtained in Figure 16. And a ripple voltage of $0.2 \%$ is shown in Figure 17. The outputs are measured with the help of power quality analyzer and it is found that the supply power factor is 0.913 which is closer to unity and also which is high compared to open loop configuration.

Table 2. THD and PF values for different control techniques.

\begin{tabular}{ccc}
\hline Control Techniques & THD\% & Supply Power factor \\
\hline Open loop configuration & 12.17 & 0.859 \\
Peak Current & 11.63 & 0.885 \\
Average Current & 8.28 & 0.896 \\
Hysteresis & 4.81 & 0.897 \\
Borderline & 3.19 & 0.905 \\
Non Linear/switch current & 3.11 & 0.913 \\
Non Linear/inductor current & 2.84 & 0.92 \\
\hline
\end{tabular}

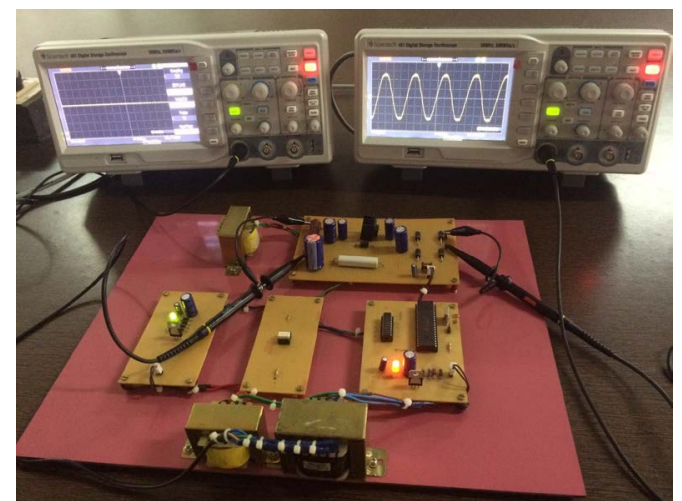

Figure 15. Proposed prototype.

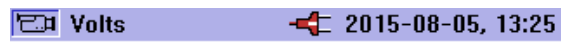

$99.9 \mathrm{~Hz}$

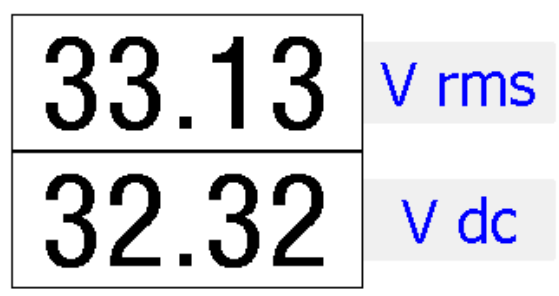

Figure 16. PRMS voltage of proposed prototype. 


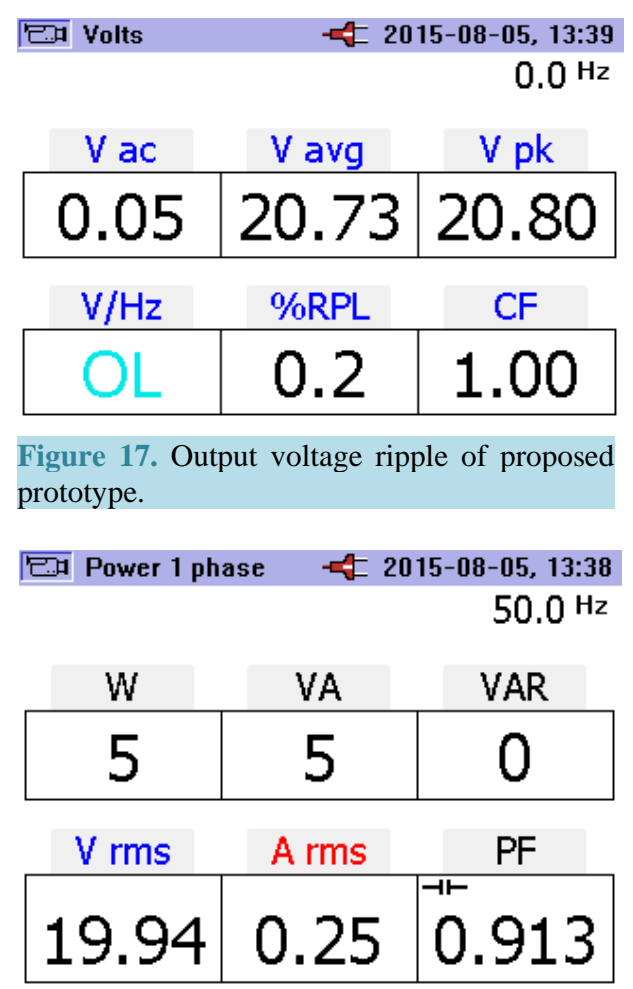

Figure 18. Supply power factor of proposed prototype (non linear inductor current).

\section{Conclusion}

This paper deals with several current control techniques specifically developed for active power factor correction. A comparative analysis of the performance parameters of peak current control, average current control, hysteresis control, borderline current control and non-linear control techniques has been carried out. From the results it is found that the, non-linear current control technique affords the least total harmonic distortion and hence, the best power factor, which validates its choice for power factor correction. The simulation results are validated experimentally. Therefore, nonlinear inductor current control will be a suitable technique to improve the power factor.

\section{Acknowledgements}

The author gratefully acknowledges the support provided by her supervisor Dr. R. Seyezhai and thanks the management of Loyola-ICAM College of Engineering and Technology for encouraging the research work.

\section{References}

[1] García, O., Cobos, J.A., Prieto, R., Alou, P. and Uceda, J. (2003) Single Phase Power Factor Correction: A Survey. IEEE Transactions on Power Electronics, 18, 749.

[2] Qiao, C.M. and Keyue Ma Smedley, (2001) A Topology Survey of Single-Stage Power Factor Corrector with a Boost Type Input-Current-Shaper. IEEE Transactions on Power Electronics, 16, 360-368.

[3] Redl, R., et al. (1994) Power Factor Correction in Single-Phase Switching Mode Power Supplies-An Overview. International Journal of Electronics, 77, 555-582. http://dx.doi.org/10.1080/00207219408926087

[4] Todd, P.C. (1995-1996) UC3854 Controlled Power Factor Correction Circuit Design. In: Unitrode Product \& Applications Handbook 1995-1996, Unitrode Corporation, Merrimack, NH, 10; 303-322.

[5] Kasakian, J.G., Schlecht, M.F. and Verghese, G.C. (1996) Principles of Power Electronics. Addison-Wesley, Reading, MA, 116.

[6] Freeland, S.D. (1988) Input Current Shaping for Single-Phase ac/dc Power Converters. Ph.D. Thesis, Part II, Cal Tech. 
[7] Nalbant, M.K. and Klein, J. (1989) Design of a 1kW Power Factor Correction Circuit. PCIM/Power Quality Conference, California, 16-19 October 1989, 17-24.

[8] Klein, J. and Nalbant, M.K. (1990) Power Factor Correction-Incentives, Standards and Techniques. PCIM Conference, Munich, 25-29 June 1990, 28-31.

[9] Wai, R.J. and Duan, R.Y. (2005) High Step-Up Converter with Coupled-Inductor. IEEE Transactions on Power Electronics, 20, 1025-1035. http://dx.doi.org/10.1109/TPEL.2005.854023

[10] Hsieh, Y.-P., Chen, J.-F., Yang, L.-S., Wu, C.-Y. and Liu, W.-S. (2014) High-Conversion-Ratio Bidirectional DC-DC Converter with Coupled Inductor. IEEE Transactions on Industrial Electronics, 61, 210-222.

[11] Chou, E., Chen, F., Adragna, C. and Lu, B. (2009) Ripple Steering AC-DC Converters to Minimize Input Filter. IEEE Energy Conversion Congress and Exposition, San Jose, 20-24 September 2009, 1325-1330. http://dx.doi.org/10.1109/ecce.2009.5316572

[12] Dixon, L. (1990) Average Current Mode Control of Switching Power Supplies. Unitrode Power Supply Design Seminar Handbook, Application Note U-140.

[13] Rossetto, L., Spiazzi, G. and Tenti P. (1994) Control Techniques for Power Factor Correction Converters. Proceedings of the International Conference on Power Electronics and Motion Control, Warsaw, September 1994, 1310-1318.

[14] Huber, L., Irving, T.B. and Jovanović, M.M. (2009) Closed-Loop Control Methods for Interleaved DCM/CCM Boundary Boost PFC Converters. 24th Annual IEEE Applied Power Electronics Conference and Exposition, Washington DC, 15-19 February 2009, 991-997.

[15] Balogh, L. and Redl, R. (1993) Power-Factor Correction with Interleaved Boost Converters in Continuous-InductorCurrent Mode. Proceedings of the 8th Annual Applied Power Electronics Conference and Exposition, San Diego, 7-11 March 1993, 168-174. http://dx.doi.org/10.1109/apec.1993.290634

[16] Lee, P., Lee, Y., Cheng, D.K.W. and Liu, X. (2000) Steady-State Analysis of an Interleaved Boost Converter with Coupled Inductors. IEEE Transactions on Industrial Electronics, 47, 787-795. http://dx.doi.org/10.1109/41.857959

[17] Miwa, B.A., Otten, D. and Schlecht, M.E. (1992) High Efficiency Power Factor Correction Using Interleaving Techniques. Proceedings of the 7th Annual Applied Power Electronics Conference and Exposition, Boston, 23-27 February 1992, 557-568.

[18] Teodorescu, R., Kjaer, S., Munk-Nielsen, S., Blaabjerg, F. and Pedersen, J. (2001) Comparative Analysis of Three Interleaved Boost Power Factor Corrected Topologies in DCM. IEEE 32nd Annual Power Electronics Specialists Conference, Vol. 1, Vancouver, 17-21 January, 3-7.

[19] Wang, J., Dunford, W.G. and Mauch, K. (1996) A Fixed Frequency, Fixed Duty Cycle Boost Converter with Ripple Free Input Inductor Current for Unity Power Factor Operation. 27th Annual IEEE Power Electronics Specialists Conference, Vol. 2, Baveno, 23-27 June 1996, 1177-1183.

[20] Cuk, S. (1980) A New Zero-Ripple Switching DC-to-DC Converter and Integrated Magnetic. Proceedings of the IEEE Power Electronics Specialists Conference, Atlanta, 16-20 June 1980, 12-32. http://dx.doi.org/10.1109/pesc.1980.7089430

[21] Kong, P.J., Wang, S. and Lee, F.C. (2008) Common Mode EMI Noise Suppression for Bridgeless PFC Converters. IEEE Transactions on Power Electronics 23, 291-297. http://dx.doi.org/10.1109/TPEL.2007.911877

[22] Zhang, W., Zhang, M.T., Lee, F., Roudet, J. and Clavel, E. (1997) Conducted EMI Analysis of a Boost PFC Circuit. 12th Annual Applied Power Electronics Conference and Exposition, Atlanta, 23-27 February, 223-229. http://dx.doi.org/10.1109/apec.1997.581457

[23] Pinheiro, J., Grundling, H., Vidor, D. and Baggio, J. (1999) Control Strategy of an Interleaved Boost Power Factor Correction Converter. 30th Annual IEEE Power Electronics Specialists Conference, 1, 137-142. http://dx.doi.org/10.1109/PESC.1999.788993

[24] Zhang, S. and Yu, X. (2012) The Output Current Analysis and Its Applications in the Interleaved Boost Converter. Proceedings of the IEEE 34th International Telecommunications Energy Conference, Scottsdale, 30 September-4 October 2012, 1-5.

[25] Zhang, S. (2012) Analysis and Minimization of the Input Current Ripple of Interleaved Boost Converter. 27th Annual IEEE Applied Power Electronics Conference and Exposition (APEC), Orlando, 5-9 February 2012, 852-856. http://dx.doi.org/10.1109/apec.2012.6165918

[26] Zhu, J. and Pratt, A. (2009) Capacitor Ripple Current in an Interleaved PFC Converter. IEEE Transactions on Power Electronics, 24, 1506-1514. http://dx.doi.org/10.1109/TPEL.2009.2014164

[27] Cheng, W.B., Song, J.X., Li, H. and Guo, Y.N. (2015) Time-Varying Compensation for Peak Current-Controlled PFC Boost Converter. IEEE Transactions on Power Electronics, 30, 3431-3437. http://dx.doi.org/10.1109/TPEL.2014.2334296 
[28] Zhou, C., Ridley, R.B. and Lee, F.C. (1990) Design and Analysis of a Hysteretic Boost Power Factor Correction Circuit. 21st Annual IEEE Power Electronics Specialists Conference, San Antonio, 11-14 Jun 1990, 800-807. http://dx.doi.org/10.1109/pesc.1990.131271

[29] Maksimovic, D., Yungtaeklang and Erickson, R.W. (1995) Nonlinear-Carrier Control for High Power Factor Boost Rectifiers. 10th Annual Applied Power Electronics Conference and Exposition, 2, 635-641. http://dx.doi.org/10.1109/apec.1995.469087 